\title{
A simplified multiplex PCR assay for fast and easy discrimination of globally distributed staphylococcal cassette chromosome mec types in meticillin- resistant Staphylococcus aureus
}

\author{
Ehsanollah Ghaznavi-Rad, ${ }^{1}$ Mariana Nor Shamsudin, ${ }^{1}$ Zamberi Sekawi, ${ }^{1}$ \\ Alex van Belkum ${ }^{2}$ and Vasanthakumari Neela ${ }^{1}$ \\ ${ }^{1}$ Department of Medical Microbiology and Parasitology, Faculty of Medicine and Health Sciences, \\ Universiti Putra Malaysia, 43400 Serdang, Selangor, Malaysia \\ ${ }^{2}$ Department of Medical Microbiology and Infectious Diseases, Erasmus MC, 's Gravendijkwal 230, \\ 3015 CE Rotterdam, The Netherlands
}

Correspondence

Vasanthakumari Neela

neela2000@hotmail.com

Received 8 May 2010

Accepted 1 July 2010

\begin{abstract}
A multiplex PCR assay was developed for the identification of major types and subtypes of staphylococcal cassette chromosome mec (SCCmec) in meticillin-resistant Staphylococcus aureus (MRSA) strains. The method uses a novel 9 valent multiplex PCR plus two primer pairs for S. aureus identification and detection of meticillin resistance. All 389 clinical MRSA isolates from Malaysia and 18 European isolates from the Harmony collection harbouring different SCCmec types that we tested were correctly characterized by our PCR assay. SCCmec type III and V were by far the most common types among both hospital- and community-acquired Malaysian MRSA isolates, with an apparent emergence of MRSA harbouring the IVh type.
\end{abstract}

\section{INTRODUCTION}

Meticillin-resistant Staphylococcus aureus (MRSA), a pathogen responsible for many nosocomial infections, was first reported in 1960 (Jevons, 1961). Over the past few decades it has emerged in the community as well, and it is currently considered a threat to public health (Lindsay \& Holden, 2004). MRSA needs to be identified below the species level by rapid and reliable typing methods. Staphylococcal cassette chromosome mec (SCCmec) typing accompanied with overall genotyping has already provided strong evidence for the independent origins of health-careassociated MRSA and community-acquired MRSA (Naimi et al., 2003). Resistance to meticillin in S. aureus is mediated by PBP2a, a penicillin-binding protein with low affinity for $\beta$-lactams, that is encoded by the mecA gene, which is located on SCCmec (Hartman \& Tomasz, 1984; Ito et al., 1999). To date, eight (Zhang et al., 2009) different types of SCCmec (I-VIII) have been defined on the basis of the combination of $c \mathrm{cr}$ and mec complexes, but only type I$\mathrm{V}$ are globally distributed, whilst others appear to exist as local strains in the country of origin (Oliveira et al., 2006; Zhang et al., 2009). The five allotypes of the $c c r$ gene complex have been named ccrAB1, ccrAB2, ccrAB3, ccrAB4

Abbreviations: IWG-SCC, International Working Group on the Classification of Staphylococcal Cassette Chromosome Elements; MRSA, meticillin-resistant Staphylococcus aureus; SCCmec, staphylococcal cassette chromosome mec; ST, sequence type. and $\operatorname{ccrC}$ (Ito et al., 2001, 2004; IWG-SCC, 2009; Oliveira et al., 2001). Hence, five classes of the mec gene complex (A-E) have been described (Ito et al., 2001; Lim et al., 2003). The regions located between these complexes are called J (joining) regions and in every SCCmec element there are three J regions (J1-J3) (Ito et al., 2003). Polymorphism in J regions (mainly J1) have been described and used for the definition of SCCmec type IV subtypes (Chongtrakool et al., 2006; Pérez-Roth et al., 2004). SCCmec type IV has eight individual subtypes, which are characteristic for some of the notorious nosocomial MRSA clones such as EMRSA-15 in European countries, and that are starting to emerge in Asian countries (Cookson et al., 2007; Ghaznavi-Rad et al., 2010; Hsu et al., 2007; Nadig et al., 2010). For SCCmec type determination different PCR methods have been described; however, they do not always generate concordant data (Boye et al., 2007; Kondo et al., 2007; Milheiriço et al., 2007b; Shore et al., 2005). Moreover with the available methods more than one multiplex PCR is required for identifying all SCCmec types, which again needs lots of optimization and is also time consuming. The availability of an easy and fast assay for the routine monitoring of SCCmec types in the hospital or community would be more advantageous. Therefore, the aim of the current study was to establish a simplified multiplex PCR assay with a combination of established PCR primer sets for the rapid and easy detection of globally distributed SCCmec types. 


\section{METHODS}

Bacterial isolates. In total, 389 non-duplicate clinical isolates of MRSA from hospitalized patients collected during the years 20072008 were used. All isolates were evaluated for the presence of the mecA gene by PCR (Milheiriço et al., 2007b). A total of 9 reference strains, including SCCmec type I (NCTC 10442), type II (N315), type III (85/2082), type IVa (JCSC 4744), type IVb (JCSC 2172), type IVc (JCSC 4788), type IVd (JCSC 4469), type IVh (HAR 22), type V (strain WIS), and 18 strains from a European reference collection of epidemic MRSA (the Harmony collection) were included as well (Cookson et al., 2007).

PCR primer sets (Table 1) were selected from published papers based on specificity, compatibility and ability to target fragments of SCCmec types I-V including type IV subtypes (Cookson et al., 2007). For genotypic confirmation of $S$. aureus, Sa442 S. aureus species-specific primers were used (Martineau et al., 1998).

Multiplex PCR. Chromosomal DNA was extracted from MRSA strains using a Qiagen DNeasy kit and a QIAcube robot (Qiagen). DNA concentration was determined using a Biophotometer (Eppendorf).

For multiplex PCR, a Qiagen multiplex PCR kit was used. Initially, the assay was optimized using reference strains. Reaction mixtures contained $1 \mu \mathrm{g}$ chromosomal DNA, $25 \mu \mathrm{l}$ master mix with $3 \mathrm{mM}$ $\mathrm{MgCl}_{2}, 5 \mu \mathrm{l}$ primer mix ( $2 \mu \mathrm{M}$ in TE buffer for each primer) and RNAse-free water to a final volume of $50 \mu \mathrm{l}$. The reaction was carried out in a Biometra T PCR system (Biometra) according to the following program: an activation step at $95{ }^{\circ} \mathrm{C}$ for $15 \mathrm{~min}$, followed by 30 cycles of initial denaturation at $94{ }^{\circ} \mathrm{C}$ for $30 \mathrm{~s}, 57^{\circ} \mathrm{C}$ for
1.5 min and $72{ }^{\circ} \mathrm{C}$ for 1.5 min, ending with a final extension step at $72{ }^{\circ} \mathrm{C}$ for $10 \mathrm{~min}$, and followed by a holding step at $4{ }^{\circ} \mathrm{C}$.

The PCR amplicons $(6 \mu \mathrm{l})$ were visualized using UV light (Alpha Imager) after electrophoresis in a $1.8 \%(\mathrm{w} / \mathrm{v})$ agarose gel containing $0.01 \mu \mathrm{l} \mathrm{GelRed} \mathrm{ml}^{-1}$ (Biotium). In order to distinguish between similarly sized amplicons MetaPhor agarose was used, which can easily discriminate amplicons differing by less than $20 \mathrm{bp}$. The SCCmec type was determined on the basis of the band pattern obtained.

Validation. The multiplex PCR assay was first optimized using control strains; the efficacy of the assay was evaluated with 389 Malaysian MRSA isolates and 18 Harmony isolates (Table 2).

\section{RESULTS}

A clear and easily discriminated band pattern was obtained for all five types and subtypes of the main SCCmec types using the new multiplex PCR (Fig. 1). Each individual PCR yielded the fragments of expected size: i.e. $613,287,243$, $776,1000,677,1242,663$ and 325 bp for subtypes I, II, III, IVa, IVb, IVc, IVd, IVh and V, respectively, and 162 and $108 \mathrm{bp}$ for the mecA gene and sa442, respectively. All the isolates were positive for mecA and a certain type of SCCmec. Evaluation of our multiplex PCR assay against 389 clinical MRSA isolates, with individual SCCmec type sequenced PCR products as the gold standard, showed $100 \%$ sensitivity and specificity (Kondo et al., 2007; Milheiriço et al., 2007b). The vast majority (92.8\%) of the Malaysian isolates carried

Table 1. Primers used for the simultaneous identification and $\mathrm{SCC} m e c$ typing of MRSA by multiplex PCR

\begin{tabular}{|c|c|c|c|c|c|c|}
\hline Primer & Orientation & Oligonucleotide sequence $\left(5^{\prime} \rightarrow 3^{\prime}\right)$ & Target gene & $\begin{array}{l}\text { Strain used } \\
\text { as standard }\end{array}$ & $\begin{array}{l}\text { Size } \\
(\mathbf{b p})\end{array}$ & Reference \\
\hline Type I & $\begin{array}{l}\text { Forward } \\
\text { Reverse }\end{array}$ & $\begin{array}{l}\text { GCTTTAAAGAGTGTCGTTACAGG } \\
\text { GTTCTCTCATAGTATGACGTCC }\end{array}$ & $\begin{array}{l}\text { ORF E008 of strain } \\
\text { NCTC10442 }\end{array}$ & NCTC 10442 & 613 & Zhang et al. (2005) \\
\hline Type II & $\begin{array}{l}\text { Forward } \\
\text { Reverse }\end{array}$ & $\begin{array}{l}\text { GATTACTTCAGAACCAGGTCAT } \\
\text { TAAACTGTGTCACACGATCCAT }\end{array}$ & $k d p E$ of strain $\mathrm{N} 315$ & N315 & 287 & Kondo et al. (2007) \\
\hline Type III & $\begin{array}{l}\text { Forward } \\
\text { Reverse }\end{array}$ & $\begin{array}{l}\text { CATTTGTGAAACACAGTACG } \\
\text { GTTATTGAGACTCCTAAAGC }\end{array}$ & J1 region of SCCmec type III & $85 / 2082$ & 243 & $\begin{array}{l}\text { Milheiriço et al. } \\
\text { (2007b) }\end{array}$ \\
\hline Type IVa & $\begin{array}{l}\text { Forward } \\
\text { Reverse }\end{array}$ & $\begin{array}{l}\text { GCCTTATTCGAAGAAACCG } \\
\text { CTACTCTTCTGAAAAGCGTCG }\end{array}$ & ORF CQ002 of strain CA05 & JCSC 4744 & 776 & Zhang et al. (2005) \\
\hline Type IVb & $\begin{array}{l}\text { Forward } \\
\text { Reverse }\end{array}$ & $\begin{array}{l}\text { AGTACATTTTATCTTTGCGTA } \\
\text { AGTCATCTTCAATATGGAGAAAGTA }\end{array}$ & $\mathrm{J1}$ region of SCCmec type IVb & JCSC 2172 & 1000 & Okuma et al. (2002) \\
\hline Type IVc & $\begin{array}{l}\text { Forward } \\
\text { Reverse }\end{array}$ & $\begin{array}{l}\text { TCTATTCAATCGTTCTCGTATT } \\
\text { TCGTTGTCATTTAATTCTGAACT }\end{array}$ & IVc element of strain $81 / 108$ & JCSC 4788 & 677 & Ma et al. (2005) \\
\hline Type IVd & $\begin{array}{l}\text { Forward } \\
\text { Reverse }\end{array}$ & $\begin{array}{l}\text { AATTCACCCGTACCTGAGAA } \\
\text { AGAATGTGGTTATAAGATAGCTA }\end{array}$ & CD002 in type IVd & JCSC 4469 & 1242 & Kondo et al. (2007) \\
\hline Type IVh & $\begin{array}{l}\text { Forward } \\
\text { Reverse }\end{array}$ & $\begin{array}{l}\text { TTCCTCGTTTTTTCTGAACG } \\
\text { CAAACACTGATATTGTGTCG }\end{array}$ & J1 region strain HAR22 & HAR22 & 663 & $\begin{array}{l}\text { Milheiriço et al. } \\
\text { (2007b) }\end{array}$ \\
\hline Type V & $\begin{array}{l}\text { Forward } \\
\text { Reverse }\end{array}$ & $\begin{array}{l}\text { GAACATTGTTACTTAAATGAGCG } \\
\text { TGAAAGTTGTACCCTTGACACC }\end{array}$ & ORF V011 of strain JCSC 3624 & WIS & 325 & Zhang et al. (2005) \\
\hline mecA & $\begin{array}{l}\text { Forward } \\
\text { Reverse }\end{array}$ & $\begin{array}{l}\text { TCCAGATTACAACTTCACCAGG3 } \\
\text { CCACTTCATATCTTGTAACG }\end{array}$ & mecA gene & ATCC29247 & 162 & $\begin{array}{l}\text { Milheiriço et al. } \\
\text { (2007b) }\end{array}$ \\
\hline Sa442 & $\begin{array}{l}\text { Forward } \\
\text { Reverse }\end{array}$ & $\begin{array}{l}\text { AATCTTTGTCGGTACACGA- } \\
\text { TATTCTTCACG } \\
\text { CGTAATGAGATTTCAGTAGA- } \\
\text { TAATACAACA }\end{array}$ & Species-specific target & - & 108 & $\begin{array}{l}\text { Martineau et al. } \\
\text { (1998) }\end{array}$ \\
\hline
\end{tabular}


Table 2. Comparison of the present study with the traditional PCR SCCmec typing method for Harmony isolates

Isolates shown in bold (97151, 1000/93, 98/26821, 76167) were newly subtyped using our protocol.

\begin{tabular}{|c|c|c|c|c|c|c|}
\hline $1155-1 / 98$ & Germany & t001 & 228 & 5 & I & I \\
\hline 18 & Slovenia & t001 & 228 & 5 & I & I \\
\hline M307-I & UK & t001 & 5 & 5 & I & I \\
\hline $96 / 32010$ & UK & t018 & 36 & 30 & II & II \\
\hline $99 / 1139$ & UK & t018 & 36 & 30 & II & II \\
\hline $99 / 159$ & UK & t018 & 36 & 30 & II & II \\
\hline $97 \mathrm{~S} 101(95 / 1119 / 3)$ & Belgium & t045 & 5 & 5 & III & III \\
\hline 98541 & Finland & $\mathrm{t} 037$ & 241 & 8 & III & III \\
\hline AK 541 & Sweden & t037 & 239 & 8 & III & III \\
\hline $1000 / 93$ & Germany (Hannover) & t009 & 254 & 8 & IV & IVh \\
\hline $98 / 26821$ & UK & $\mathrm{t} 1275$ & 22 & 22 & IV & IVh \\
\hline 76167 & Finland & t015 & 45 & 45 & IV & IVc \\
\hline
\end{tabular}

CC, Clonal complex; MLST, multilocus sequence typing; spa, staphylococcal protein A encoding gene.

${ }^{\star}$ Kondo et al. (2007).

SCCmec type III, while $22(5.7 \%)$ isolates harboured SCCmec type V and 6 (1.5\%) were demonstrated to contain SCCmec type IVh. The results obtained for the European Harmony collection are summarized in Table 2. All results are in accordance with those obtained by established

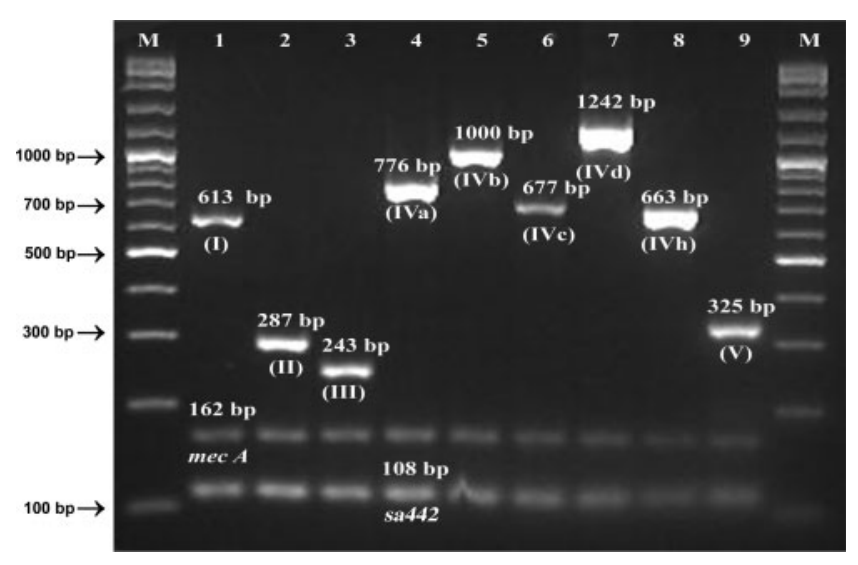

Fig. 1. Validation and application of the SCCmec multiplex PCR. Lane 1, SCCmec type I (NCTC 10442); lane 2, type II (N315); lane 3, type III (85/2082); lane 4, type IVa (JCSC 4744); lane 5, type IVb (JCSC 2172); lane 6, type IVc (JCSC 4788); lane 7, type IVd (JCSC 4469); lane 8, type IVh HAR22; lane 9, type V (WIS); $\mathrm{M}$, DNA molecular mass size marker (VC 100 bp Plus DNA ladder; Vivantis). methods (Cookson et al., 2007). All the type V isolates were confirmed by the presence of the $\operatorname{ccr} C$ gene, and six sequence type (ST)-22 IVh strains were assigned by the ccrA2B2 and type B mec element.

\section{DISCUSSION}

The multiplex PCRs optimized by Oliveira \& de Lencastre (2002) have been used for assigning SCCmec elements based on the identification of eight loci (A to $\mathrm{H}$ ), mostly located in the J regions. The PCRs were updated for the identification of the SCCmec type V but the system is still limited due to its inability to discriminate SCCmec subtypes IVa, b, c, d and h; however, an individual multiplex PCR dedicated for the subtyping of the class IV was described simultaneously (Milheiriço et al., 2007a). In addition, due to the presence of common elements, such as $c c r A 2 B 2$ in type II and IV or the class A mec gene in types II and III, complex comparison procedures and sometimes difficult interpretation may compromise the final results (Milheiriço et al., 2007b). The most informative and robust method to determine SCCmec types was introduced by Kondo et al. (2007), but five different multiplex PCRs with 34 pairs of primers are required. Hence, routine application is considered cumbersome. Recently, a new and apparently simple method was introduced by Boye et al. (2007) using four sets of primers only. However, this method will only identify major SCCmec types. The advantages of the method we present here, as compared to the method of Boye et al. (2007), is that subtyping of type IV 
SCCmec is feasible. We found that six of our clinical isolates and three Harmony MRSA strains, which were earlier reported as type IV (ST-254-MRSA-IV, ST-22-MRSA-IV and ST-8-MRSA-16), were categorized now as type IVh. MRSA with such cassettes are currently penetrating Asian countries, but have thus far been hard to detect in Singapore and Taiwan (Hsu et al., 2007; Huang et al., 2006). The possible emergence of a new SCCmec type in the future cannot be neglected as seen with SCCmec type VI to VIII; hence, reconfiguration of the assay will be necessary when significant numbers of new SCCmec type strains have evolved.

In Malaysian hospitals, the MRSA prevalence ranges from 5.6 to $33.7 \%$, with an overall rate of $26 \%$ (Ministry of Health, 2008). Most hospital-acquired MRSA belong to ST239 III/IIIA (Ghaznavi-Rad et al., 2010) and EMRSA 15 IVh strains are emerging. In addition, increasing numbers of community-acquired MRSA of ST188, SCCmec type V are being detected (Nor Shamsudin et al., 2008). The new assay developed herein was successful in typing MRSA regardless of their clinical source, clonality, demography, period of isolation and ethnicity of the people the MRSA isolates came from. Although the majority of the isolates tested were of SCCmec type III, the correct typing of harmony isolates confirms the reliability of the assay.

Comparison of our new assay with the traditional PCR SCCmec typing method (including mec and $\mathrm{ccr}$ gene complex typing) and the assay of Milheiriço et al. (2007b) demonstrated $100 \%$ sensitivity and specificity when testing a number of control strains. Our multiplex PCR assay does not conflict with any of the PCRs reported before (Kondo et al., 2007; Milheiriço et al., 2007b). The new method is a combination of earlier PCRs, but with an optimized PCR protocol that can be applied effectively for the routine diagnosis and epidemiological typing of SCCmec in MRSA.

\section{Conclusions}

We have successfully simplified the protocol of SCCmec typing to allow rapid and reliable assignment of SCCmec types to MRSA strains. This strategy is more robust in its ability to characterize most known SCCmec types and subtypes, and genotypically confirms $S$. aureus as well as meticillin resistance in a single tube.

\section{ACKNOWLEDGEMENTS}

We are grateful to Professor Teruyo Ito (Juntendo University, Japan) for providing reference SCCmec type strains and confirming the SCCmec type IVh MRSA isolates. We express our special thanks to Dr Willem van Leeuwen (Erasmus MC, Rotterdam, The Netherlands) for strains derived from the European HARMONY collection. This work was supported by the Ministry of Science, Technology and Innovation Malaysia (MOSTI) Science Fund by grant numbers 06-01-04-SF0885 and 02-01-04-SF0853.

\section{REFERENCES}

Boye, K., Bartels, M. D., Andersen, I. S., Møller, J. A. \& Westh, H. (2007). A new multiplex PCR for easy screening of methicillin- resistant Staphylococcus aureus SCCmec types I-V. Clin Microbiol Infect 13, 725-727.

Chongtrakool, P., Ito, T., Ma, X. X., Kondo, Y., Trakulsomboon, S., Tiensasitorn, C., Jamklang, M., Chavalit, T., Song, J. H. \& Hiramatsu, K. (2006). Staphylococcal cassette chromosome mec (SCCmec) typing of methicillin-resistant Staphylococcus aureus strains isolated in 11 Asian countries: a proposal for a new nomenclature for SCCmec elements. Antimicrob Agents Chemother 50, 1001-1012.

Cookson, B. D., Robinson, D. A., Monk, A. B., Murchan, S., Deplano, A., de Ryck, R., Struelens, M. J., Scheel, C., Fussing, V. \& other authors (2007). Evaluation of molecular typing methods in characterizing a European collection of epidemic methicillin-resistant Staphylococcus aureus strains: the HARMONY collection. J Clin Microbiol 45, 18301837.

Ghaznavi-Rad, E., Shamsudin, M. N., Sekawi, Z., Khoon, L. Y., Aziz, M. N., Hamat, R. A., Othman, N., Chong, P. P., van Belkum, A. \& other authors (2010). Predominance and emergence of clones of hospitalacquired methicillin-resistant Staphylococcus aureus in Malaysia. J Clin Microbiol 48, 867-872.

Hartman, B. J. \& Tomasz, A. (1984). Low-affinity penicillin-binding protein associated with $\beta$-lactam resistance in Staphylococcus aureus. J Bacteriol 158, 513-516.

Hsu, L. Y., Loomba-Chlebicka, N., Koh, Y. L., Tan, T. Y., Krishnan, P., Lin, R. T., Tee, N. W., Fisher, D. A. \& Koh, T. H. (2007). Evolving EMRSA-15 epidemic in Singapore hospitals. J Med Microbiol 56, 376379.

Huang, Y. C., Su, L. H., Wu, T. L. \& Lin, T. Y. (2006). Changing molecular epidemiology of methicillin-resistant Staphylococcus aureus bloodstream isolates from a teaching hospital in Northern Taiwan. J Clin Microbiol 44, 2268-2270.

Ito, T., Katayama, Y. \& Hiramatsu, K. (1999). Cloning and nucleotide sequence determination of the entire mec DNA of pre-methicillinresistant Staphylococcus aureus N315. Antimicrob Agents Chemother 43, 1449-1458.

Ito, T., Katayama, Y., Asada, K., Mori, N., Tsutsumimoto, K., Tiensasitorn, C. \& Hiramatsu, K. (2001). Structural comparison of three types of staphylococcal cassette chromosome mec integrated in the chromosome in methicillin-resistant Staphylococcus aureus. Antimicrob Agents Chemother 45, 1323-1336.

Ito, T., Okuma, K., Ma, X. X., Yuzawa, H. \& Hiramatsu, K. (2003). Insights on antibiotic resistance of Staphylococcus aureus from its whole genome: genomic island SCC. Drug Resist Updat 6, 41-52.

Ito, T., Ma, X. X., Takeuchi, F., Okuma, K., Yuzawa, H. \& Hiramatsu, K. (2004). Novel type V staphylococcal cassette chromosome mec driven by a novel cassette chromosome recombinase, $c c r C$. Antimicrob Agents Chemother 48, 2637-2651.

IWG-SCC (2009). Classification of staphylococcal cassette chromosome mec (SCCmec): guidelines for reporting novel SCCmec elements. Antimicrob Agents Chemother 53, 4961-4967.

Jevons, M. P. (1961). “Celbenin”-resistant staphylococci. BMJ 1, 124125.

Kondo, Y., Ito, T., Ma, X. X., Watanabe, S., Kreiswirth, B. N., Etienne, J. \& Hiramatsu, K. (2007). Combination of multiplex PCRs for staphylococcal cassette chromosome mec type assignment: rapid identification system for mec, $c c r$, and major differences in junkyard regions. Antimicrob Agents Chemother 51, 264-274.

Lim, T. T., Chong, F. N., O’Brien, F. G. \& Grubb, W. B. (2003). Are all community methicillin-resistant Staphylococcus aureus related? A comparison of their mec regions. Pathology 35, 336-343.

Lindsay, J. A. \& Holden, M. T. (2004). Staphylococcus aureus: superbug, super genome? Trends Microbiol 12, 378-385. 
Ma, X. X., Galiana, A., Pedreira, W., Mowszowicz, M., Christophersen, I., Machiavello, S., Lope, L., Benaderet, S., Buela, F. \& other authors (2005). Community-acquired methicillin-resistant Staphylococcus aureus, Uruguay. Emerg Infect Dis 11, 973-976.

Martineau, F., Picard, F. J., Roy, P. H., Ouellette, M. \& Bergeron, M. G. (1998). Species-specific and ubiquitous-DNA-based assays for rapid identification of Staphylococcus aureus. J Clin Microbiol 36, 618623.

Milheiriço, C., Oliveira, D. C. \& de Lencastre, H. (2007a). Multiplex PCR strategy for subtyping the staphylococcal cassette chromosome mec type IV in methicillin-resistant Staphylococcus aureus: 'SCCmec IV multiplex'. J Antimicrob Chemother 60, 42-48.

Milheiriço, C., Oliveira, D. C. \& de Lencastre, H. (2007b). Update to the multiplex PCR strategy for assignment of mec element types in Staphylococcus aureus. Antimicrob Agents Chemother 51, 3374-3377.

Ministry of Health (2008). National Surveillance of Antibiotic Resistance Report. Malaysia: Ministry of Health. http://www.imr.gov. my/report/Summary\%20of\%20antibiotic\%20resistance\%202008.doc

Nadig, S., Ramachandra Raju, S. \& Arakere, G. (2010). Epidemic meticillin-resistant Staphylococcus aureus (EMRSA-15) variants detected in healthy and diseased individuals in India. $J \mathrm{Med}$ Microbiol 59, 815-821.

Naimi, T. S., LeDell, K. H., Como-Sabetti, K., Borchardt, S. M., Boxrud, D. J., Etienne, J., Johnson, S. K., Vandenesch, F., Fridkin, S. \& other authors (2003). Comparison of community- and health careassociated methicillin-resistant Staphylococcus aureus infection. JAMA 290, 2976-2984.

Nor Shamsudin, M., Sekawi, Z., van Belkum, A. \& Neela, V. (2008). First community-acquired meticillin-resistant Staphylococcus aureus in Malaysia. J Med Microbiol 57, 1180-1181.

Okuma, K., Iwakawa, K., Turnidge, J. D., Grubb, W. B., Bell, J. M., O'Brien, F. G., Coombs, G. W., Pearman, J. W., Tenover, F. C. \& other authors (2002). Dissemination of new methicillin-resistant Staphylococcus aureus clones in the community. J Clin Microbiol 40, 4289-4294.

Oliveira, D. C. \& de Lencastre, H. (2002). Multiplex PCR strategy for rapid identification of structural types and variants of the mec element in methicillin-resistant Staphylococcus aureus. Antimicrob Agents Chemother 46, 2155-2161.

Oliveira, D. C., Tomasz, A. \& de Lencastre, H. (2001). The evolution of pandemic clones of methicillin-resistant Staphylococcus aureus: identification of two ancestral genetic backgrounds and the associated mec elements. Microb Drug Resist 7, 349-361.

Oliveira, D. C., Milheirico, C. \& De Lencastre, H. (2006). Redefining a structural variant of staphylococcal cassette chromosome mec, SCCmec type VI. Antimicrob Agents Chemother 50, 3457-3459.

Pérez-Roth, E., Lorenzo-Díaz, F., Batista, N., Moreno, A. \& MéndezAlvarez, S. (2004). Tracking methicillin-resistant Staphylococcus aureus clones during a 5 -year period (1998 to 2002) in a Spanish hospital. J Clin Microbiol 42, 4649-4656.

Shore, A., Rossney, A. S., Keane, C. T., Enright, M. C. \& Coleman, D. C. (2005). Seven novel variants of the staphylococcal chromosomal cassette mec in methicillin-resistant Staphylococcus aureus isolates from Ireland. Antimicrob Agents Chemother 49, 2070-2083.

Zhang, K., McClure, J. A., Elsayed, S., Louie, T. \& Conly, J. M. (2005). Novel multiplex PCR assay for characterization and concomitant subtyping of staphylococcal cassette chromosome mec types I to V in methicillin-resistant Staphylococcus aureus. J Clin Microbiol 43, 50265033.

Zhang, K., McClure, J. A., Elsayed, S. \& Conly, J. M. (2009). Novel staphylococcal cassette chromosome mec type, tentatively designated type VIII, harboring class A mec and type $4 \mathrm{ccr}$ gene complexes in a Canadian epidemic strain of methicillin-resistant Staphylococcus aureus. Antimicrob Agents Chemother 53, 531-540. 